\title{
Tumoral calcinosis: a manifestation of extreme metastatic calcification occurring with 1, $\alpha$-hydroxycholecalciferol therapy
}

\author{
G. S. WALKER \\ B.Sc., M.B., Ch.B., M.R.C.P. \\ A. M. Davison \\ B.Sc., M.B., Ch.B., M.R.C.P. \\ M. Peacock $\dagger$ \\ M.B., Ch.B., M.R.C.P. \\ M. S. F. MCLACHLAN* \\ M.D., F.R.C.P. \\ Department of Renal Medicine, *Department of Diagonostic Radiology, St. James's University \\ Hospital and †M.R.C. Mineral Metabolism Unit, Leeds General Infirmary, Leeds
}

\begin{abstract}
Summary
Two cases are reviewed, both of which developed tumoral calcinosis whilst receiving $1, \alpha$-hydroxycholecalciferol therapy. Tumoral calcinosis is an extreme form of peri-articular calcification, and its occurrence in patients with chronic renal failure is unusual. These peri-articular masses developed around the shoulders in both patients, and the action of $1, \alpha-$ hydroxycholecalciferol as a possible factor promoting this form of metastatic calcification is discussed.
\end{abstract}

\section{Introduction}

The association of metastatic calcification with chronic renal disease was first described by Virchow (1855). A full review of the subject by Mulligan (1947) confirmed the association between these two conditions, but it was not until the advent of regular haemodialysis therapy that widespread metastatic calcification became an important clinical problem (Kleeman et al., 1967). The metastatic calcification that develops in patients with chronic renal disease can occur in several forms and one of these is periarticular calcification (Parfitt, 1969). A severe form of peri-articular calcification, called tumoral calcinosis, has been described as a separate entity (Inclan, 1943). It is characterized by a large, rubbery or cystic calcified mass occurring close to a large joint.

Tumoral calcinosis has been infrequently reported in patients with chronic renal disease (Barton and Reeves, 1961; Curtis and Feller, 1942; Burkholder and Braund, 1947; Levin and Genovesse, 1950). These case reports stress that a considerable number of years must elapse before soft tissue calcification of such severity can develop in patients with chronic renal disease. Tumoral calcinosis has also been reported in patients given massive doses of vitamin

Correspondence: G. S. Walker, University Department of Renal Medicine, Withington Hospital, Manchester.
D for arthritic diseases (Chaplin, Clark and Ropers, 1951; Holman, 1952; Christensen, Liebman and in Sosman, 1951).

The experience with massive doses of vitamin $\mathrm{D}_{\circ}$ would suggest that vitamin $D$ stimulates the pro- $\supset$ gression of metastatic calcification to produce $\vec{C}$ tumoral calcinosis. This has important implications $\mathbb{O}$ for all patients with renal disease, and two patients $\underset{\mathbb{D}}{\mathbb{O}}$ with chronic renal failure are reviewed who do- 3 veloped tumoral calcinosis on $1, \alpha$-hydroxychole- $\underline{-}$ calciferol therapy, a potent synthetic vitamin $\overrightarrow{0}$ analogue.

\section{Case reports \\ Case 1}

A 41-year-old white male presented with glomerulonephritis in October 1968 and started regular haemodialysis in January 1972. He was established $\mathscr{Q}$ on home dialysis and started on $2 \mu \mathrm{g}$ daily of $1, \alpha-\overrightarrow{\overrightarrow{0}}$ hydroxycholecalciferol $\left(1, \alpha-\mathrm{OHD}_{3}\right.$ in March 1975.3 This was increased to $3 \mu \mathrm{g}$ daily because of a poor response as assessed by the intestinal absorption of radiocalcium. The dose of $3 \mu \mathrm{g}$ daily was continuedo응 until October 1975 when it was then reduced to $2 \mu \mathrm{g}$. daily because of intractable pruritus. The plasma calcium increased on therapy (from $2.88 \mathrm{mmol} / 1$ to $3.19 \mathrm{mmol} / \mathrm{l}$ ), and throughout the time on $1, \alpha-0$ $\mathrm{OHD}_{3}$ it remained at around $3.00 \mathrm{mmol} / \mathrm{l}$. The plasma phosphate was initially high in this patient at 음 $3.08 \mathrm{mmol} / \mathrm{l}$ and it continued in the range $2.20->$ $2.80 \mathrm{mmol} / \mathrm{l}$. Assessment of intestinal absorption showed an increase for calcium absorption from N $0.44 / \mathrm{hr}$ to $0.74 / \mathrm{hr}$, and an increase for phosphorus absorption from $0 \cdot 27 / \mathrm{hr}$ to $0 \cdot 50 / \mathrm{hr}$. The activity of parathyroid hormone was high initially at $51.3 \mathrm{ng} / \mathrm{ml}$ and after 7 months was even higher at $85.5 \mathrm{ng} / \mathrm{ml} \underset{\sim}{\widetilde{O}}$

The dialysis regimen was standard and remainedo unchanged after starting $1, \alpha-\mathrm{OHD}_{3}$ therapy. The patient was maintained on a Meltec $1.5 \mathrm{~m}^{2}$ multi- - ? point dialyser for 4 hours three times a week, and 
the dialysate calcium concentration was kept at 1.5 $\mathrm{mmol} / \mathrm{l}$. After several months of therapy the patient complained of severe pruritus and developed acute 'red-eyes'. Radiological assessment at this time failed to find any evidence of an increase in soft tissue calcification. Examination of the cornea by slit lamp after 6 months of therapy again failed to detect any change in metastatic calcification.

In early December 1975 he was started on a regular dose of phosphate binding agent (aluminium hydroxide gel) in order to lower his plasma phosphate concentration and so improve the pruritus. He continued taking this regularly until July 1976 when the $1, \alpha-\mathrm{OHD}_{3}$ was withdrawn. The plasma phosphate concentration remained unchanged even on large doses of aluminium hydroxide gel $(80-100 \mathrm{ml}$ daily), however, his symptoms of pruritus and grittiness in the eyes improved.

In July 1976 the patient presented with a hard, cystic swelling overlying the clavicle near the right shoulder. Radiological examination showed this to be calcified (Fig. 1). The swelling had developed relatively rapidly, and apart from one short episode of pain following cessation of $1, \alpha-\mathrm{OHD}_{3}$ was painless. Since the $1, \alpha-\mathrm{OHD}_{3}$ therapy was withdrawn there has been no further pruritus and the calcified mass has regressed in size.

\section{Case 2}

A 52-year-old white female developed terminal renal failure secondary to polycystic renal disease and commenced regular haemodialysis in February 1974. She was established on hospital dialysis and started on $2 \mu \mathrm{g}$ daily of $1, \alpha-\mathrm{OHD}_{3}$ in March 1975. This dose was continued without any change until it was stopped in mid-May 1976. The plasma calcium did not change on therapy, and on no occasion was it above $3.00 \mathrm{mmol} / 1$. The plasma phosphate showed an initial increase in the early weeks (from $2.66 \mathrm{mmol} / 1$ to $3.00 \mathrm{mmol} / \mathrm{l}$ ), but this soon settled and throughout the remainder of the study period was in the range $2 \cdot 25-2 \cdot 80 \mathrm{mmol} / 1$. Assessment of intestinal absorption showed an increase for calcium absorption from $0.23 / \mathrm{hr}$ to $0.93 / \mathrm{hr}$, and a change in phosphorus absorption from $0 \cdot 42 / \mathrm{hr}$ to $0 \cdot 39 / \mathrm{hr}$. The activity of parathyroid hormone was high initially at $11.6 \mathrm{ng} / \mathrm{ml}$ and after 7 months was unchanged at $12 \cdot 7 \mathrm{ng} / \mathrm{ml}$.

The dialysis regimen remained standard as in case 1. The patient started complaining of severe pruritus after several months on $1, \alpha-\mathrm{OHD}_{3}$ and at times it was so intense that she stopped taking the compound for 2 or 3 weeks. Radiological assessment at 6 months showed some increase in peri-articular calcification, but this was very marked at the end of 14 months (Fig. 2). Examination of this patient's cornea also showed evidence of an increase in calcification over this period. The aluminium hydroxide gel was started in mid-December 1975 to try to control the patient's pruritus, unfortunately it had little
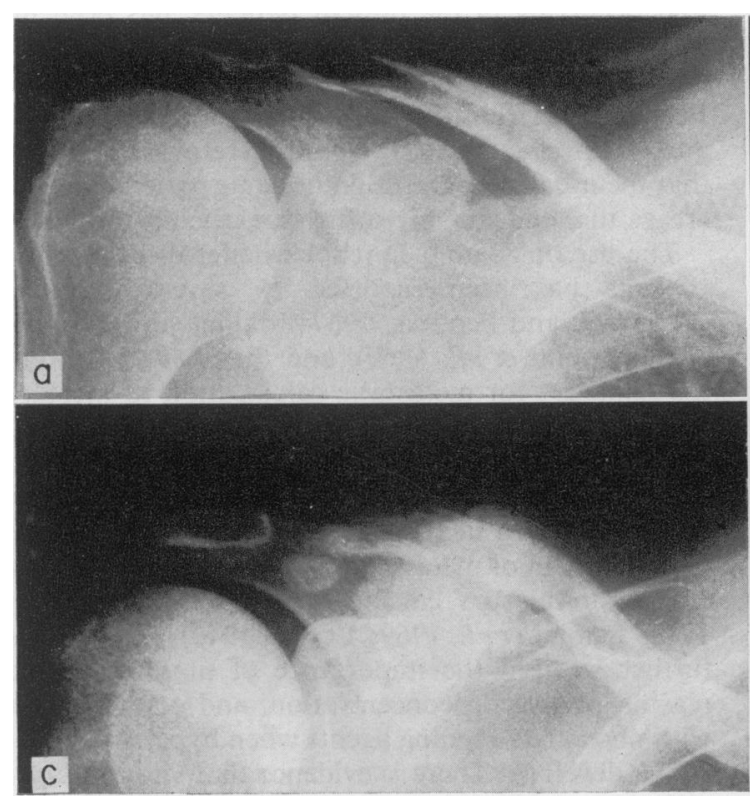

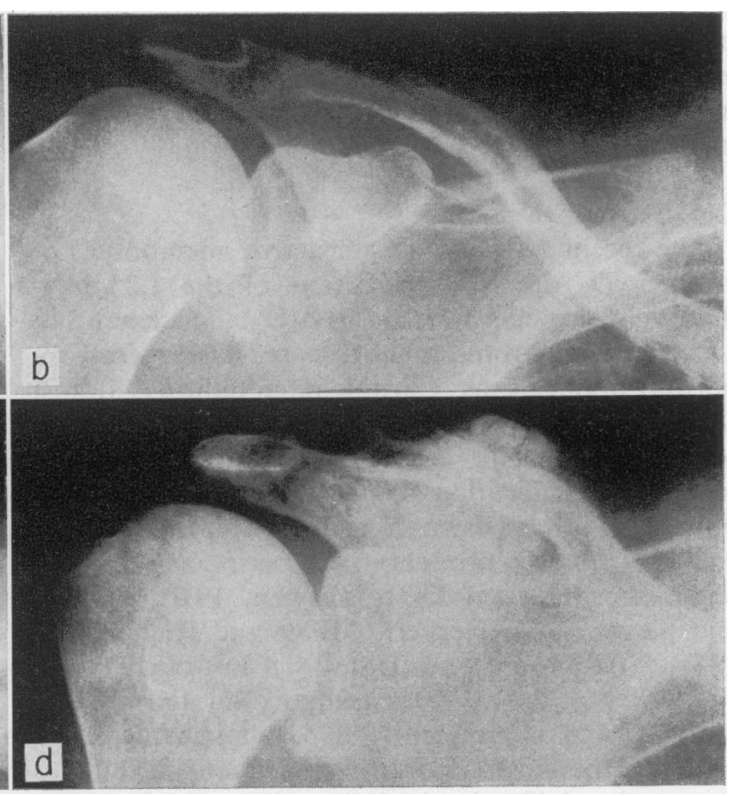

FIG. 1. Right shoulder at (a) 15.11 .74 ; (b) 15.8 .75 ; (c) 30.4 .76 ; (d) 28.6 .76 . 


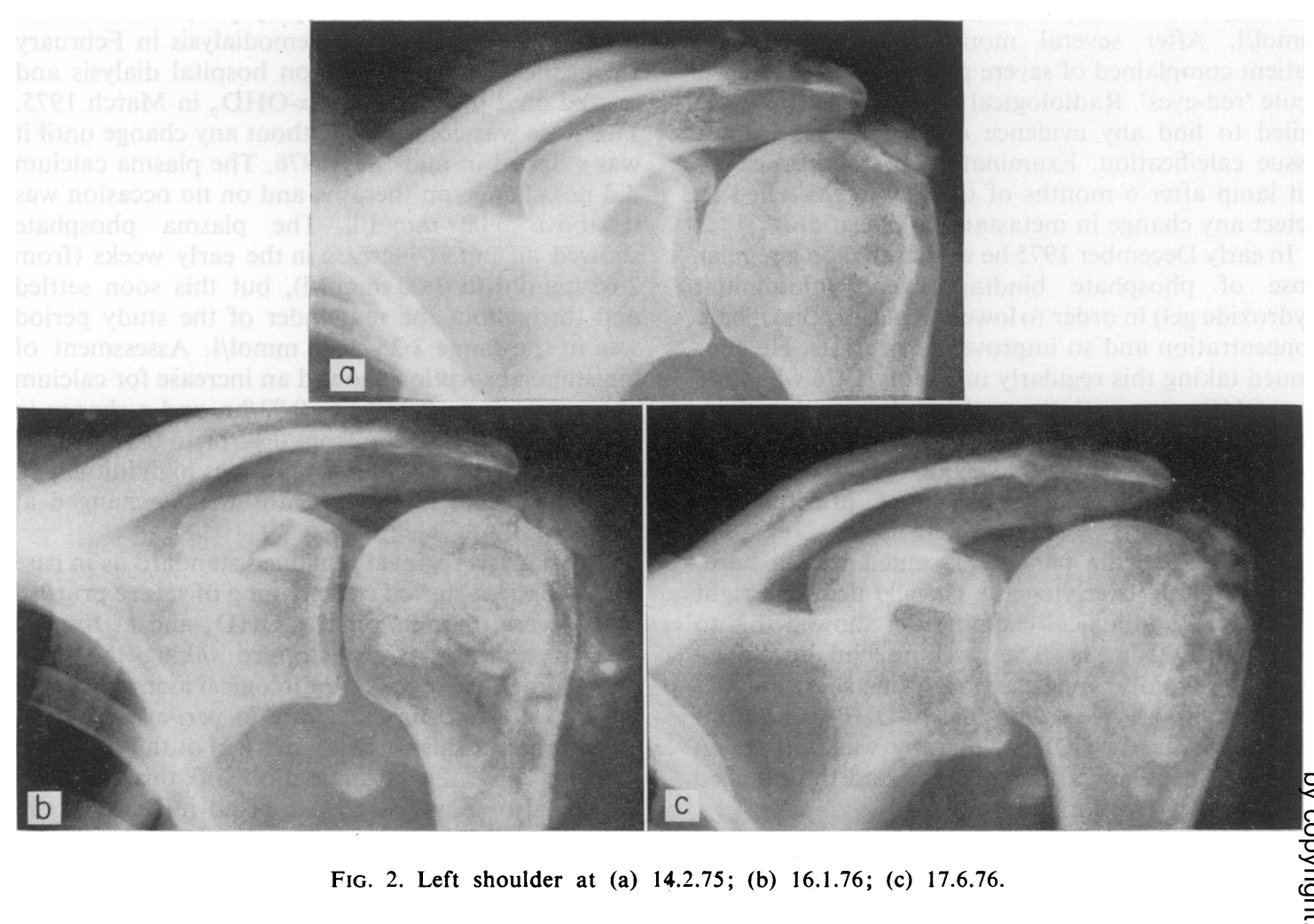

effect on either the plasma phosphate concentration or the symptoms of pruritus. As the pruritus was very severe the patient stopped taking the $1, \alpha-\mathrm{OHD}_{3}$ in May 1976. Since that time she has been free of the pruritus.

\section{Discussion}

The recent introduction of 'active' metabolites of vitamin $D_{3}$, for the correction of the 1,25 , dihydroxy-cholecalciferol $\left(1,25-(\mathrm{OH})_{2} \mathrm{D}_{3}\right)$-deficiency that accompanies chronic renal disease, has several important implications. Chronic renal failure is almost always associated with metastatic calcification of some degree. The aetiology of this widespread metastatic calcification is undoubtedly multifactoral, but it has always been considered that a high calcium-phosphorus product in the peripheral blood is the most important factor (Logan, 1940; Berlyne and Shaw, 1967; Herbert, Miller and Richardson, 1941). The plasma phosphate level in uraemia may vary over a much wider range than the plasma calcium, and consequently hyperphosphataemia is probably the most important single factor leading to metastatic calcification in these patients (Parfitt 1969). The extreme example of metastatic calcification as that occurring in the present patients, has been infrequently reported in association with chronic renal disease (Barton and Reeves, 1961; Curtis and Feller, 1942; Burkholder and Braund 1947; Levin and Genovesse, 1950). It would therefore seem likely that the use of $1, \alpha-\mathrm{OHD}_{3}$ in uraemic patients can increase the tendency for soft tissue calcification.

The use of vitamin D (cholecalciferol) in uraemic patients has been reported by several workers (Davidson and Pendras, 1967; Mallick and Berlyne, 1968; Rubini et al., 1969), and they have all found the tendency for metastatic calcification to increase during a period of therapy. The mechanism may involve a change in the calcium-phosphorus product, and it would seem that the plasma phosphate is the most important factor, as vitamin D can stimulate the formation of metastatic calcification without any change in plasma calcium (Mallick and Berlyne, 1968; Rubini et al., 1969; Logan, 1940). Mallick has further stressed the importance of monitoring the plasma phosphate concentration, and controlling it with phosphate binding agents when hyperphosphataemia develops. There is evidence that vitamin $\mathbf{D}$ itself may predispose to metastatic calcification as studies in rabbits (Hass et al., 1958) have shown that 
vitamin $\mathbf{D}$ can produce soft tissue calcification in many sites without associated change in plasma calcium or phosphate levels.

Whatever the mechanism, there is no doubt that vitamin D therapy has been associated with an increase in metastic calcification in uraemic patients, and rarely with the formation of tumoral calcinosis (Chaplin et al., 1951; Holman 1952; Christensen et al., 1951). From this report, it can be seen that $1, \alpha-$ $\mathrm{OHD}_{3}$ has at least the same potential as massive doses of vitamin $D$ for inducing extensive soft tissue calcification. The mechanism is in doubt, it may play a direct role at the tissue sites, or it may produce its effect through changes in the calcium-phosphorus product. $1, \alpha-\mathrm{OHD}_{3}$ is known to enhance intestinal calcium absorption in uraemic patients (Peacock $e t$ al., 1975), and to induce hypercalcaemia. Furthermore, studies from the authors' group (Peacock, Davison and Walker, 1977), have shown that $1, \alpha-\mathrm{OHD}_{3}$ is active in uraemic patients on maintenance haemodialysis, and is associated with an increase in the intestinal absorption of phosphorus as well as calcium. The consequences of this increase in intestinal phosphorus absorption is to enhance the tendency to hyperphosphataemia. Thus, $1, \alpha-\mathrm{OHD}_{3}$, through its ability to increase both the plasma calcium and plasma phosphate concentrations, is capable of dramatically changing the calciumphosphorus product.

This capacity of $1, \alpha-\mathrm{OHD}_{3}$ to change the calciumphosporus product, and through this or other mechanisms, to enhance the rate of metastatic calcification, should be remembered by all clinicians using the compound. The use of phosphate binding agents can certainly reduce the calcium-phosphorus produce (Peacock et al., 1977). It is for this reason, that all patients on $1, \alpha-\mathrm{OHD}_{3}$ therapy should be regularly seen, and if the calcium-phosphorus product increases, the use of phosphate binding agents becomes mandatory. Finally, the authors suggest that the clinical symptom of pruritus is a useful way of detecting early metastatic calcification and should therefore be considered as an early warning of more serious problems.

\section{Acknowledgments}

G. S. Walker is supported in his work by the Yorkshire Kidney Research Fund.

\section{References}

Barton, D.L. \& Reeves, R.J. (1961) Tumoral Calcinosis: Report of three cases and review of the Literature. American Journal of Roentgenology, 86, 351.
Berlyne, G.M. \& Shaw, A.G. (1976) Red eyes in renal failure. Lancet, i, 4.

BURKHOLdeR, T.M. \& BRAUND, R.R. (1947) Massive calcinosis with chronic renal insufficiency due to polycystic kidneys: case report. Journal of Urinology, 57, 1001.

Chaplin, R., Clark, L.D. \& Ropers, M.W. (1951) Vitamin D intoxication. American Journal of Medical Science, 221, 369.

Christensen, W.R., Liebman, C. \& Sosman, M.C. (1951) Skeletal and periarticular manifestations of hypervitaminosis D. Americal Journal of Roentgenology, 65, 27.

Curtis, L.E. \& Feller, A.E. (1942) Hyperparathyrodism with calcinosis and secondary to renal disease: report of a probable case. Annals of Internal Medicine, 17, 1005.

Davidson, R.C. \& Pendras, J.P. (1967). Calcium-related cardiorespiratory death in chronic hemodialysis. Transactions of the American Society of Artificial Internal Organs, 13, 36.

Hass, G.M., Trueheart, R.E., Taylor, C.B. \& Stumpe, M. (1958) An experimental histologic study of hypervitaminosis D. American Journal of Pathology, 34, 395.

Herbert, F.K., Miller, H.G. \& Richardson, G.O. (1941) Chronic renal disease, secondary parathyroid hyperplasmia decalcification of bone and metastic calcification. Journal of Pathology and Bacteriology, 53, 161.

Holman, C.B. (1952) Roentgenologic manifestations of vitamin D intoxication. Radiology, 59, 805.

INCLAN, A. (1943) Tumoral calcinosis. Journal of the American Medical Association, 121, 490.

Kleeman, C.R., Better, D., Massry, S.G. \& Maxwell, M.H. (1967) Divalent ion metabolism and osteodystrophy in chronic renal failure. Yale Journal of Biology and Medicine, 40, 1.

Levin, R.T. \& Genovesse, P.D. (1950) Report of a case of long-standing renal insufficiency with extensive metastatice calcification (renal osteitis fibrosa cystica). American Journal of Roentgenology, 64, 423.

LOGAN, M.A. (1940) Recent advances in the chemistry of calcification. Physiological Review, 20, 522.

Mallick, N.P. \& Berlyne, G.M. (1968) Arterial calcification after vitamin $D$ therapy in hyperphosphataemic renal failure. Lancet, ii, 1316.

Mulligan, R.M. (1947) Metastatic calcification. Archives of Pathology, 43, 177.

Parfitr, A.M. (1969) Soft tissue calcification in uraemia. Archives of Internal Medicine, 124, 544.

Peacock, M., Nordin, B.E.C., Gallagher, J.C. \& VarNAVIDES, C. (1975) Action of $1, \alpha$-hydroxy vitamin $D_{3}$ in man. In: Vitamin $D$ and Problems Related to Uraemic Bone Disease. P 611. Ed. by A. W. Norman, K. Schaefer, H. G. Grigoleit, D. Herrath and E. Ritz. Walter de Grayter, Berlin, New York.

Peacock, M., Davison, A.M. \& Walker, G.S. (1976) The effect of plasma phosphate on the action of $1, \alpha$-hydroxycholecalciferol in haemodialysis patients. Proceedings of the Second International Workshop on Phosphate. Advances in Experimental Medicine and Biology, 81, 559.

Rubini, M.E., Coburn, J.W., MasSry, S.G. \& ShinaBERGER, J.H. (1969) Renal osteodystrophy. Archives of Internal Medicine, 124, 663.

VIRCHOw, R. (1955) Kalkmetastasen. Virchows Archiv für Pathologische Anatomie und Physiologie und für klinische Medizin, 8, 103. 